\title{
DIGITALIZATION OF COMMUNICATION AND THE SPIRAL OF SILENCE THEORY
}

\begin{abstract}
This article discusses the issue of the influence of digital technologies on manifestations and transformation of the spiral of silence phenomenon. An analysis is given on the role of the Internet as a public sphere, and the results of recent researches on the spiral of silence manifestations on online-based platforms are discussed. The author comes to the conclusion that manifestations of the spiral of silence are crucial in the process of the development of the Internet as a public sphere, and, communicative, technological and social-psychological factors, discussed in this paper, will determine whether and how onlinebased platforms will enhance democracy.
\end{abstract}

Keywords: spiral of silence, digital communication, media, Internet, social media, information, public sphere.

\section{Introduction}

The spiral of silence theory is one of the most remarkable approaches regarding public opinion and its role in society. It was developed in the 1970 s by German political scientist and sociologist Elizabeth Noelle-Neumann. The theory is based on the irrational approach towards public opinion, which is perceived to control the members of society and keeps its integrity by defining what is moral or immoral, good or bad, right or wrong. Noelle-Neumann develops the key concepts of her theory based on previous philosophical approaches of public opinion. In particular, she highlights Russo's view, who considers public opinion as an unwritten law and discusses its power from a moral point of view, instead of intellectual. The views of John Locke, James Madison and David Hume regarding the relationship of individual and society were also fundamental for Noelle-Neumann in developing one of the key concepts of her theory - the irrational fear of isolation. The significance of her theory is that besides combining these approaches, she provided them with empirical base due to numerous researches through years.

The spiral of silence theory has faced many challenges, the most important of which was the rise of online public space as one of the main platforms of opinion expression. Many studies have been conducted in recent years to reveal whether the theory works on digital platforms. However, the results are contradictory and suggest a mixed picture. On the one hand, digitalization of communication enhanced information and opinion sharing opportunities and provided a space for open and horizontal communication. On the other hand, the architecture of these privately owned spaces shaped new rules, different from face to face communication. Thus, not all 
researchers today share the early optimistic view regarding the Internet as a public sphere, which was expected to increase the user's willingness to express an opinion, boost rational debates and enhance democracy.

\section{Public Opinion according to the Spiral of Silence Theory}

Elizabeth Noelle-Neumann articulated her theory as an attempt to explain the willingness to express an opinion based on a few social and psychological approaches interpreting group thinking and behaviour (Athanesyan \& Ter-Harutyunyan, 2017, pp. 79-84). According to Noelle-Neumann (1996), the guiding mechanism leading [to] opinion expression in public is the irrational feeling of being isolated (p. 40). If people consider their opinion as dominant or likely to become such, they tend to express it publicly. If they decide that opinion is on the minority side or is likely to become such, they tend to show conformity and choose to remain silent (Liu \& Fahm, 2011, pp. 46-47).

Noelle-Neumann contradicts her theory to those approaches, which explain human behaviour and public opinion from the point of view of rationalism and which dominated among academics through the $19^{\text {th }}$ and $20^{\text {th }}$ centuries. These approaches identified public opinion with rationality, which they assumed as a process of knowledge gaining through intelligence and forming logical judgments based on it (Childs, 1965; Sauerwein, Dafoe, Stern-Rubarth., Haswell Lutz, Dwight Lasswell, \& Wright, 1933; Speier, 1950; Young, 1923). Noelle-Neumann states that such an approach shows only the hidden function of public opinion - opinion formation under democracy. Whereas public opinion also has a latent function, neglected by rationalist approaches - social control through the irrational fear of being isolated.

Noelle-Neumann (1996) defines public opinion as a morally shaped opinion and behaviour, which is necessary to show off around people without being afraid of isolation (p. 282). It is based on the non-conscious intention of people, living in a certain community, to gain agreement necessary for decision making and taking action in certain circumstances. The author analyzes public opinion as a social-psychological process of social control, which is rooted in an individual's fear of being isolated. Public opinion is the society's "social skin" maintaining its integrity and vitality. Despite driving people to conformity and restricting their freedom, public opinion is still necessary for them and society in general.

Another basic premise of Noelle-Neumann's (1996) theory is that people are rather perceptible towards public opinion climate and have a certain notion about it by scanning their environment despite any statistical data available (p. 47). Therefore, the so-called "quasistatistical ability to evaluate public opinion climate" does not mean that people are able to feel it accurately. Noelle-Neumann considers isolation from dissent groups as the main factor weakening that ability and causing a phenomenon she calls "pluralistic ignorance". The less opinion congruency between representatives from opposite poles, the stronger polarization is (Noelle-Neumann, 1996, pp. 222-240).

In the process of environmental monitoring, people's evaluation of public opinion climate is shaped through direct and indirect channels. Direct channels include face to face discussions, communication during protests and other actions. The main indirect channel is the media, which presents opinion polls results, polls conducted on the streets, general sentiment of news, etc. (Kim, 
2017, p. 3). Noelle-Neumann stresses the importance of media information, which often becomes the only available reality for people. The media sets issues and structures them, thus setting agenda. It also assures an individual's selective perception and protects from cognitive dissonance (Noelle-Neumann, 1996, pp. 237-240). Stereotypes play a significant role in this process triggering conformity and making the discussed topic clearer. Besides discussion topics, the media also provides people with the necessary vocabulary for expressing their opinion.

The spiral of silence theory raised many discussions among academics and drove researchers from various disciplines to test its main hypotheses. The meta-analyses conducted in 1997 demonstrated that perceptions of public opinion climate have a little, but statistically significant impact on the willingness to express an opinion (Glynn, Hayes, \& Shanahan, 1997). The authors explain the mixed results by the methodological issues the theory faced since NoelleNeumann has started its testing. They assume that the results might differ if the researchers had observed people's actual behaviour instead of asking how they would behave in a hypothetic situation. New meta-analyses conducted in 2017 included the application of the theory on the web (Matthes, Knoll, \& von Sikorski, 2018). It states a positive correlation between perceived opinion climate and the willingness to express an opinion, moreover, the spiralling process in digital platforms does not decrease. It is notable that the research results were the same in Europe, USA and Asia, which demonstrates that the spiral of silence works both in individualist and collectivist societies. It is worth to mention that not all surveys confirm the absence of cultural differences. Some authors, however, claim that attitudes towards the willingness to express opinion differ among societies. In the USA a man expressing his own opinion is perceived as competent, friendly and intelligent. Whereas in collectivist societies expressing opinion may be considered as impolite. A research conducted in Singapore did not reveal any correlation between an individual's free or community-oriented selfconcept and his or her willingness to speak out (Willnat, Lee, \& Detenber, 2002). Such a mixed picture proves that intercultural research on the spiral of silence theory is still needed.

\section{The Main Features of \\ Digital Platforms}

In the $1990^{\mathrm{s}}$ as a result of the rise of digital technologies and the World Wide Web the spiral of silence theory received a renewed attention, raising new questions: will the spiralling process continue in the computer-mediated environment and, if it does, how? To answer these questions first, we need to analyze the Internet as a public space. According to Manuale Casstels (2001), the main features of the web are its openness and horizontal and free communication (pp. 54-55). These characteristics brought to democratization and globalization of public space and public opinion, thus bringing public discourse to a transnational level (Iosifidis \& Wheeler, p. 21). In parallel, the researchers got the opportunity to study the spiral of silence phenomenon in behavioural level instead of using hypothetic situations they used to suggest before.

Despite early expectations that enhanced technological and communicational opportunities will make the Internet one abstract place or a global village, where people will be involved in public discussions, researchers still don't have a clear answer whether the Internet is a public space or a public sphere. According to the con- 
cept's author, Jurgen Habermas, the public sphere is an abstract mediation between the state and society, a discursive arena where individuals engaged in rational discussion, deliberation, agreement and action in order to attain a democratic consensus and, ultimately, to achieve a common good, in an egalitarian and pluralistic environment (Malaspina, 2014, pp. 29-32). The development of the World Wide Web since its invention has demonstrated that the processes occurring in online-based spaces do not much the mentioned Habermasian definition of the public sphere.

On the web, people's involvement in public discussions has been rapidly growing, but not everyone and not equally got access to them. The equality may be injured by technological or network limitations and low level of media literacy. Even in the case of equal technology, those with a low level of income and education use the web for different purposes than those with higher income and education level (Lupton, 2015, p. 124). For the latter digital technologies serve as a means to improve their own cultural, economic and educational level, whereas those with low income and educational level tend to use the web mainly for social interactions and virtual games (van Deursen \& van Dijk, 2014, pp. 510-511).

Yochai Benkler has made an attempt to integrate Habermas's approach with network theory. He considers the networked structure of the web and its topology as key factors affecting the spread of information online. It enables enough saturation for the links and prevents fragmentation or information flow control by one of the network nodes. In the 1990s due to the development of information economy, new websites and blogs were developed, which were free from advertising and sponsorship and published news in non-traditional journalistic approach, free from "fashionable" opinions and tastes (Rasmussen, 2014, pp. 1322). However, it is worth to mention that digital technologies took rise under capitalism, which drove to their inevitable commercialization. Like television, online-based platforms became overloaded with advertising, which brought their commercial functions to the first plan. At this rate, free platforms with modest resources for promotion are put in a less beneficial condition.

Johanna van Dijk also states that commercialization of online-based platforms affects the quality of online social interactions. Social media blurred barriers between private, corporate and public spaces and determines the nature of social actions (van Dijck, 2013, pp. 18-23). The author uses the term "culture of connectivity" to define these processes. The cultural experience in social media is shaped by algorithms, protocols and defaults. As a result, sociality is being modified by coded structures and digital architecture. Users realize that their data can be used for commercial purposes, and still they continue active, communicative practices, as social media provides them with the best platform for the Castellsian mass self-communication. The hierarchic and competitive structure of social media also triggers the users to seek for more popularity and to be more active. In today's attention economy, social media produces such key values as attention and reputation. Facebook's business model is based on these values, and the user's will to share data. In this regard, critics of social media warn about risks regarding privatization of web spaces by corporations. Van Dijk (2013) notes that in the modern online environment only Wikipedia, not being co-opted by big business, remains as "an uncomfortable reminder of what the Web could have been" (p. 16).

Christian Fuchs (2014) highlights three 
main social media antagonisms which hinder the formation of a democratic public sphere in these platforms (p. 78):

- Economic - Users' interest in data protection and corporate tax accountability on the one side and corporate tax accountability on the one side, and corporations' interest in user data's transparency/commodification and corporate secrecy on the other side.

- Political - Citizens' interest to hold the powerful accountable and protect communications from powerful institutions' access on the one side, and on the other side power holders' interest to keep power structures secret and to criminalize the leaking and making-public of any data about them.

- Civil society - Networked protest communication that creates public political spheres online and offline, and the particularistic corporate and state control of social media that limits feudalizes and colonizes these public spheres.

The author assumes that above-mentioned antagonisms colonize the public sphere on social media by corporations and state. Therefore, social media, despite its potential to become a public sphere, actually is not public and free and challenges the main postulates of classical liberalism. This contradicts the Habermasian understanding of public sphere, who considers it not just as a sphere of political communication, but a sphere free from economic and political power, censorship and ownership (Habermas, 1996, p. 377).

One of the obstacles for the democratic potential of the web is the difficulty to check manipulative online information (Holt, 2004, pp. 16-20). Of course, this issue is familiar to nondigital mediums also, but the problem of fake information across digital platforms is more complicated considering the volume and speed of its spread. If in the case of television, the source of manipulative information is the media itself, on social networking platforms, the users also become one of its spreading sources. Recent research on Twitter has revealed that fake news stories are $70 \%$ more likely to be retweeted than truthful ones (Vosoughi, Roy, \& Aral, 2018). It is worth to mention that the potential of onlinebased platforms to shape the public sphere depends not only on technology but also on society's political culture (McChesney, 1995, pp. 105106). Castells states that under political legacy crisis, the web cannot be a solution itself for it. Despite open, free and horizontal communication, barriers between gossips, fake and valuable political information get more and more blurred. As a result, it gets more difficult for politicians to rely on informational tools (Castells, 2001, pp. 155-158).

At the rise of World Wide Web development forums and blogs were the main platforms for online discussions. Here the users could register with anonymous accounts, which provided optimism for many researchers that the web could become a public sphere. Anonymity was supposed to reduce negative sanctions towards the ones expressing the minority opinion, as users were not physically present at the discussion and could hide their real identity. However, further studies did not completely support this assumption (Yun \& Park, 2011; Porten-Cheé \& Eilders, 2015; Liu \& Fahm, 2011).

At the beginning of 2000 s, the rise of the Web 2.0 revitalized the development of social media providing new opportunities for two-sided mass communication and digital media based on participation and interactivity. Social media sites rapidly grew and became the main online platform for opinion expression and public discus- 
sions, outgoing forums and blogs. Social media sites are both public and private platforms, where users can express their opinion through a public or private status and a message. They combine interpersonal and mass communication.

Van Dijk highlights the following characteristics of social media as a mass communication medium (van Dijck \& Poell, 2013, pp. 5-11):

- Programmability - the ability of a central agency to manipulate content in order to define the audience's watching experience as a continuous flow.

- Popularity - mass media's power in terms of agenda-setting or pushing certain topics to the fore and make their popularity measurable and quantified.

- Connectivity - the ability of a social platform to connect the content, users activities and advertisers.

- Datafication - the ability of networked platforms to render into data many aspects of the world that have never been quantified before.

As we shall see further, abovementioned features significantly determine the degree the spiral of silence theory can be applied to the online setting and on social media platforms in particular.

\section{The Factors Affecting Opinion Expression and Modernization of Spiral of Silence Theory in Frames of Digitalization}

The rise of social media platforms brought new challenges for researchers of the spiral of silence theory. The research methodology for applications of the theory on social media vary, and the results are mixed. One of the first researches on the topic, conducted by Gearhart and Zhang, have revealed that the spiral of silence continues spinning on Facebook, as users' network on this platform is mainly based on their offline connections. The will of self-censorship also has a negative influence on the user's decision to leave a public comment on a specific topic (Gearhart \& Zhang, 2014).

Some researchers have shown that the interest in politics, level of trust and participation and persistency of political views also contribute to online political activism (Hayes, Smock, \& Carr, 2015). Other studies have revealed that like offline environment, where a small network may stimulate opinion expression, on social media the bigger the network and its member's opinion diversity are, the lower an individual's willingness to express an opinion is (Brandade, Liders, $\&$ Skjetne, 2010). Moreover, users with large online network tend to delete their publications more often. Despite the controllability of information disclosure through changing privacy settings on social media, even publications available only for friends may reach bigger audiences, than a face to face conversation in train. Such publicity may also decrease the willingness to express an opinion. The number of online friends and opinion diversity may also cause an information overload, which prompts inaccurate perceptions of public opinion and pluralistic ignorance.

Another basic feature of social media that deserves close attention is its unique toolkit different from face to face communication. Here an opinion can be presented as a short comment with or without links, which contains more information than could be presented under face to face communication. Hypertext allows to accomplish a verbal opinion with audio and visual content or present it in non-direct forms, using symbols and visual tools. Finally, on social media, users can express their opinion simply using 
"like"-s and reactions. Many social media users actively follow discussions, but don't comment or limit their reaction to a "like". As a result, civic participation also transforms on social media. Digital communicative actions become the main indicator of participation, thus digitizing it and limiting actions to a discourse of the issue.

Due to mass communication on social media users' opinions quickly reach not only their online friends but also other audiences outside their network. Online media also contributes to this process, often sharing opinions not only by public figures or politicians but also by ordinary users. Thus, users' opinions on social media are not just shaping public opinion: they become news. Users get informed about public opinion without the media's agency, directly from their online friends, friends of friends, etc. Journalists and media no longer play the role of goalkeepers in the process of news flow. Users are news creators and consumers, and the content they create serves as news and means of interpersonal communication at the same time.

One of the key factors affecting the shaping of public opinion on social media is the news consumption culture. Unlike traditional media, news on social media surrounds people constantly and everywhere. News is consumed in parallel with entertaining content and is often presented in an entertaining format, thus boosting infotainment. In this regard it is worth to mention Habermas's (1996) worries regarding the increase of the role of advertising in the public sphere, as a result of which economic logic spreads through the media and depoliticizes it: "Reporting facts as human-interest stories, mixing information with entertainment, arranging material episodically, and breaking down complex relationships into smaller fragments all of this comes together to form a syndrome that works to depoliticize public communication" (p. 377). On contemporary social media platforms, this can be considered as the main tendency for communication and public discussion practices. Therefore, the spread of information and its consumption on social media, despite its technological advances and networked structure, not always enhances democratic discourse. Basically, we deal with communication for the sake of communication and Mcluhan's famous phrase "Medium is the message" can be reformulated as "Communication is the communication" or, as Castells cited: "Network is the communication".

Today's news consumption culture is also affected by digitalization and new rules of the media market. While setting agenda newsmakers are guided by marketing strategies trying to catch the audience's emotional reactions and satisfy their preferences. The audience is a busy and distracted mass of consumers, which must be satisfied at any price, even trampling on the principles of journalistic professionalism (Coleman \& Blumer, 2009, pp. 42-67).

The algorithmic logic of social media also plays a significant role in news consumption and public opinion formation. The algorithms decide which publications a user can see, based on his or her online behaviour. This contains risk of polarization, as a user starts seeing homogenous content, which usually interprets issues from one point of view. But the algorithms are only one side of the problem, besides human cognitive and psychological factors. People tend to search for information confirming their beliefs (Schulz \& Roessler, 2012, pp. 357-359). As a result, diversity of opinions creates an isolated homogenous environment instead of stimulating discussions between opposite poles (Wilhelm, 2000, pp. 86-104). Such homogenous environments, called echo chambers, make fake diversity of 
opinions and surround a user with similar views. These processes are another key factor resulting pluralistic ignorance: a representative from each pole surrounded mainly with one point of view ascribes it to the majority.

In 2014-2015 Eytan Bakhshi and other researchers studied publications of $10.1 \mathrm{mln}$ Facebook users, who actively expressed their political orientation online (Bakshy, Messing \& Adamic, 2016). Three groups of users based on political orientation have been discovered - liberals (4.1 men), moderate users $(4.4 \mathrm{mln})$ and conservatives $(4.4 \mathrm{mln})$. These groups vary not only by political orientation but also topics of shared publications and link sources. One of the key findings of the research is that in the cascade of ideological filters, besides the network and algorithms, the main obstacle to get familiar with dissent views is the user's free will: they tend to read publications by like-minded people and dislike the ones made by representatives of the opposite pole. The homogenous environment on social media contributes to the formation of a close circle of like-minded opinions. The risk of negative feedback also decreases the users' willingness to express an opinion (Gearhart \& Zhang, 2015). Lee and Famm (2011) consider the latter a key factor triggering the spiral of silence process online. They argue that isolated homogenous environment can stimulate opinion expression on social media, but at the same time, it contributes pluralistic ignorance. Homogeneity of social media refers not only to the content but also to the sentiment of opinions. Some researchers have demonstrated that political discourse on social media is mainly irrational, emotional and aggressive (Malaspina, 2014). In particular, publications representing the majority's opinion on Twitter have a higher level of emotionality than those of the minority (Luo, Li, Wang, Xue, Liu,
\& Wang, 2016).

Another important factor affecting the willingness to express an opinion on social media is the self-presentational concern. Social media has become one of the main platforms for individual's self-expression and public image presentation. Any published information becomes a part of users' digital identity and functions as a symbol for their self-presentation. Although some researches have revealed a positive correlation between self-presentation on Facebook and willingness to express political views, everything depends on the purpose and character of selfpresentation. If a man is tended to an acquisitive self-presentation, which aims to form a longterm positive public image, he or she is expressing opinion more actively. If an individua's selfpresentation is protective and aims to avoid criticism, he or she will avoid speaking under high opinion diversity (Lia, Raymond, \& Xi, 2017).

Some researches have shown that the willingness to express an opinion on social media is determined by the observation of public opinion. It is notable that in some cases, it affects the willingness to express an opinion and the fear of isolation does not (Xiaodong \& Li, 2016). This is explained by the domination of weak ties on the digital environment and the easiness to apply negative sanctions towards those with the opposite opinion. Nuebaum and Cramer also emphasize the role of situational factors which determine an individual's fear of isolation (Neubaum \& Krämer, 2016). They assume that various contextual factors, such as familiarity of the audience or communication channel, the effect on an individual's expectations concerning negative sanctions if he/she represents the minority's view. Interestingly, the research has demonstrated that people tend to express deviant opinion in offline environment and for unfamiliar audiences 
more often than they do on Facebook. Authors explain this with negative sanctions and the easiness to apply them on online-based platforms. Other studies have shown another factor affecting the willingness to express an opinion on social media - opinion congruency (Hampton, Rainie, Lu, Dwyer, Shin, \& Purcell, 2014). People avoid speaking out when they notice that their opinion differs from the one among their online network or general public opinion (Dubois \& Szwarc, 2018).

\section{Conclusion}

Analyses of the Internet as a public sphere shows that applications of the spiral of silence in this multilevel and complicated environment are specific and contradictory. On the one hand, it offers new technological and communicative features for discussion and opinion expression, which differ from face to face communication; on the other hand, it maintains some characteristics of offline sociality.

As a result of the analyses, the following factors determining applications of the spiral of silence on the online-based environment can be highlighted:

- Social media platforms, due to their logic based on connectivity and popularity, have become the main space, where people express their opinion.

- Social media platforms are owned by corporations with business models aimed to get profit.

- Online media is commercialized, and web content is colonized by corporations.

- A different news consumption culture is being developed based on infotainment and news flow, constantly surrounding the users.
- Brain's cognitive processes prompt the users to seek and share information and opinions confirming their existing beliefs.

- The polarized and homogenous environment is raising new forms of pluralistic ignorance.

- Open and horizontal communication and easy-to-use online tools and platforms stimulate the opinion expression, but, at the same time, make the fear of being criticized one of the key factors prompting the spiral of silence.

The researches have not provided a comprehensive answer to the question - whether the spiral of silence spins on social media. However, contradictory conclusions provide a stimulus for new research, especially considering the value of the question in the context of the web as a public sphere. Basically, the spiral of silence on social media affects the web's democratic potential and its further research can shed light to another key question - will the web ever transform into a public sphere from a public space? These questions are important from the philosophical point of view as well, as they will provide a new empirical basis for further understanding of the individual-society relationship and the role of public opinion in it.

\section{REFERENCES}

Athanesyan, A. V., \& Ter-Harutyunyan, A. S. (2017). Sovremennye kriticheskye teorii SMI, Aktual'nye voprosi massovoi informatsii i politicheskikh komunikatsii (Contemporary Critical Theories of Media. Actual Questions of Mass Information and Political Communication, in Russian). Yerevan: YSU Publication. 
Bakshy, E., Messing, S., \& Adamic, L. (2016). Exposure to Ideologically Diverse News and Opinion on Facebook. Science, 348(6239), 1130-1132.

Brandtzaeg, P. B., Liders, M., \& Skjetne J. H. (2010). Too Many Facebook "Friends"? Content Sharing and Sociability Versus the Need for Privacy in Social Network Sites, International Journal of Human-Computer Interaction, 26, 1006-1030.

Castells, M. (2001). The Internet Galaxy. Reflections on the Internet, Business, and Society. Oxford University Press.

Childs, H. (1965). Public Opinion: Nature, Formation, and Role. Princeton University Press.

Coleman, S., \& Blumler, J. (2009). The Internet and the Democratic Citizenship, Theory, Practice and Policy. Cambridge University Press.

Dubois, E., \& Szwarc, J. (2018). Self-Censorship, Polarization, and the "Spiral of Silence" on Social Media. Policy \& Politics Conference. Retrieved April 08, 2020 from: http://blogs.oii.ox.ac.uk/policy/wp-content/uploads/sites/77/ 2018/08/IPP2018-Dubois.pdf.

Fuchs, Ch. (2014). Social Media and the Public Sphere. Journal for a Global Sustainable Information Society, 12(1), 57-101.

Gearhart, Sh., \& Zhang, W. (2014). Gay Bullying and Online Opinion Expression: Testing Spiral of Silence in the Social Media Environment. Social Science Computer Review, 32(1), 18-36.

Gearhart, Sh., \& Zhang, W. (2015). "Was It Something I Said?" "No, It Was Something You Posted!" A Study of the Spiral of Silence Theory in Social Media
Contexts. Cyberpsychology, Behavior and Social Networking, 18, 208-213.

Glynn, C. J., \& Park, E. (1997). Reference Groups, Opinion Intensity, and Public Opinion Expression. International Journal of Public Opinion Research, 9(3), 213232.

Glynn, C., Hayes, A., \& Shanahan, J. (1997). Perceived Support for One's Opinions and Willingness to Speak out: a MetaAnalysis of Survey Studies on the "Spiral of Silence". The Public Opinion Quarterly, 61(3), 452-463.

Habermas, J. (1996). Between Facts and Norms. Contributions to a Discourse Theory of Law and Democracy. Cambridge, MA: MIT Press.

Hampton, K. N., Rainie, L., Lu, W., Dwyer, M., Shin, I., \& Purcell, K. (2014). Social Media and the 'Spiral of Silence'. Pew Research Center: Internet \& Technology. Retrieved February 29, 2020 from: https://www.pewinternet.org/2014/08/2 6/social-media-and-the-spiral-of-silence/.

Hayes, R., Smock, A., \& Carr, C. (2015). Face[book] Management: Self-Presentation of Political Views on Social Media. Pew Research Center: Internet \& Technology. Retrieved February 29, 2020 from: https://www.tandfonline. com/doi/full/10.1080/10510974.2015.1 018447.

Holt, R. (2004). Dialogue on the Internet: Language, Civic Identity, and ComputerMediated Communication Civic Discourse for the Third Millennium. Greenwood Publishing Group.

Iosifidis, P., \& Wheeler, M. (2016). Public Spheres and Mediated Social Networks in 
the Western Context and Beyond. London: Palgrave Macmillan.

Kim, S., Han, M., Shanahan, J., \& Bernays, V. (2004). Talking on "Sunshine in North Korea": A Test of the Spiral of Silence as a Theory of Powerful Mass Media. International Journal of Public Opinion Research, 16(1), 39-62.

Kim, S.-H. (2017). Spiral of Silence: Fear of Isolation and Willingness to Speak Out. Retrieved February 29, 2020 from: https://onlinelibrary.wiley.com/doi/abs/ 10.1002/9781118783764.wbieme0037.

Lia, Y., Raymond, J., \& Xi, C. R. (2017). Are People Willing to Share their Political Opinions on Facebook? Exploring Roles of Self-Presentational Concern in Spiral of Silence. Computers in Human Behavior, 76, 294-302.

Liu, X., \& Fahm, Sh. (2011). Exploring the Spiral of Silence in the Virtual World: Lndividuals' Willingness to Express Personal Opinions in Online versus Offline Settings. Journal of Media and Communication Studies, 3(2), 45-57.

Luo, L., Li, M., Wang, Q., Xue, Y., Liu, Ch., \& Wang, Zh. (2016). Spiral of Silence in Social Networks: A Data-Driven Approach. Proceedings of IEEE/ACM International Conference on Advances in Social Networks Analysis and Mining (ASONAM). doi: 10.1109/ASONAM. 2016.7752359.

Lupton, D. (2015). Digital Sociology. New York: Routledge.

Malaspina, C. (2014). The Spiral of Silence and Social Media: Analysing Noelle-Neumann's Phenomenon Application on the Web during the Italian Political Elections of 2013. London School of
Economics and Political Science, 2932.

Matthes, J., Knoll, J., \& von Sikorski, Ch. (2018). The "Spiral of Silence". Revisited: A Meta-Analysis on the Relationship between Perceptions of Opinion Support and Political Opinion Expression. Communication Research, 45(1), 3-33.

McChesney, R. (1995). The Internet and US Communication Policy-Making in Historical and Critical Perspective. Journal of Computer-Mediated Communication 1(4). Retrieved February 29, 2020 from: https://academic.oup.com/jcmc /article/1/4/JCMC142/4584372.

Neubaum, G., \& Krämer, N. (2016). What Do We Fear? Expected Sanctions for Expressing Minority Opinions in Offline and Online Communication. Communication Research, 45(2), 139-164.

Noelle-Neumann, E. (1996). Obshchestvennoe mnenie. Otkritie spirali molchaniya (Public opinion. The Discovery of Spiral of Silence, in Russian). Moscow: Progress-Academy publishing-house.

Provencher, P., \& Eilders, Ch. (2015). Spiral of Silence Online: How Online Communication Affects Opinion Climate Perception and Opinion Expression Regarding the Climate Change Debate. Studies in Communication Sciences, 15(1), 143-150.

Rasmussen, T. (2014). Internet and the Political Public Sphere. Sociology Compass, 8(12), 1315-1329.

Sauerwein, J. A., Dafoe, J. W., Stern-Rubarth, E., Haswell Lutz, R., Dwight Lasswell, H., \& Wright, Q. (1933). Public Opinion and World Politics. University of 
Chicago Press.

Schulz, A., \& Roessler, P. (2012). The Spiral of Silence and the Internet: Selection of Online Content and the Perception of the Public Opinion Climate in Computer-Mediated Communication Environment. International Journal of Public Opinion Research, 24(3), 346-367.

Speier, H. (1950). Historical Development of Public Opinion. American Journal of Sociology, 55(4), 376-388.

van Deursen, A., \& van Dijk, J. (2014). The Digital Divide Shifts to Differences in Usage. New Media \& Society 16(3), 507-526.

van Dijck, J. (2013). The Culture of Connectivity. A Critical History of Social Media. Oxford University Press.

van Dijck, J., \& Poell, Th. (2013). Understanding Social Media Logic. Media and Communication, 1(1), 2-14.

Vosoughi, S., Roy, D., \& Aral, S. (2018). The Spread of True and False News Online.
Science, 359(6380), 1146-1151.

Wilhelm, A. (2000). Democracy in the Digital Age: Challenges to Political Life in Cyberspace. London: Routledge.

Willnat, L., Lee, W., \& Detenber, B. (2002). Individual Level Predictors of Public Outspokenness: A Test of the Spiral of Silence Theory in Singapore. International Journal of Public Opinion Research, 14(4), 391-412.

Xiaodong, Y., \& Li, L. (2016). Will the Spiral of Silence Spin on Social Networking Sites? An Experiment on Opinion Climate, Fear of Isolation and Outspokenness. China Media Research, 12(1), 7987.

Young, J. T. (1923). The New American Government and its Work. New York: Macmillan \& Co.

Yun G., \& Park S. (2011). Selective Posting: Willingness to Post a Message Online. Journal of Computer-Mediated Communication, 16, 201-227. 